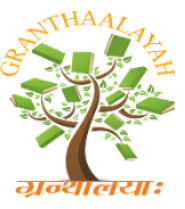

\author{
INTERNATIONAL JOURNAL OF RESEARCH - \\ GRANTHAALAYAH \\ A knowledge Repository
}

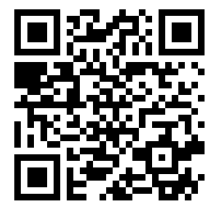

Science

\title{
SOIL EROSION AS A FUNCTION OF NATURAL AND ANTHROPOGENIC FACTORS AND ITS ENVIRONMENTAL CONSEQUENCES
}

\author{
Professor RAE. Z.H. Aliyev ${ }^{* 1}$ \\ ${ }^{* 1}$ Institute of Soil Science and Agrochemistry of ANAS, Azerbaijan
}

\begin{abstract}
The article examines the issues of the possibility of studying erosion and its control. The study proved that the development of soil erosion is based on the forming impact of natural and anthropogenic factors. The degree of potential danger and the possibility of prevention, taking into account the preservation of the environmental situation in the foothills of the Upper Shirvan in the example of the Shamakhi district of the Republic of Azerbaijan, were studied. The main tasks of the study were the determination of the amount and the degree of development of eroded and erosion-prone soils of the foothill zones, carried out on the basis of soil.
\end{abstract}

Keywords: Erosion Soil; The Assessment of the Degree of Erosion is Environmentally Hazardous; Anti-Erosion Measures.

Cite This Article: Professor RAE. Z.H. Aliyev. (2019). "SOIL EROSION AS A FUNCTION OF NATURAL AND ANTHROPOGENIC FACTORS AND ITS ENVIRONMENTAL CONSEQUENCES." International Journal of Research - Granthaalayah, 7(5), 186-192. https://doi.org/10.29121/granthaalayah.v7.i5.2019.838.

\section{Introduction}

The territory of Azerbaijan is under the ecological impact of the catchment valley of the Caspian Sea. Here, environmental problems, the solution of which are regional and depend on interstate relations, and for this reason, day after day they become strained. It must be said that the soil is exposed to erosion, forest plantations, mountain groves, water sources and other natural formations are out of order.

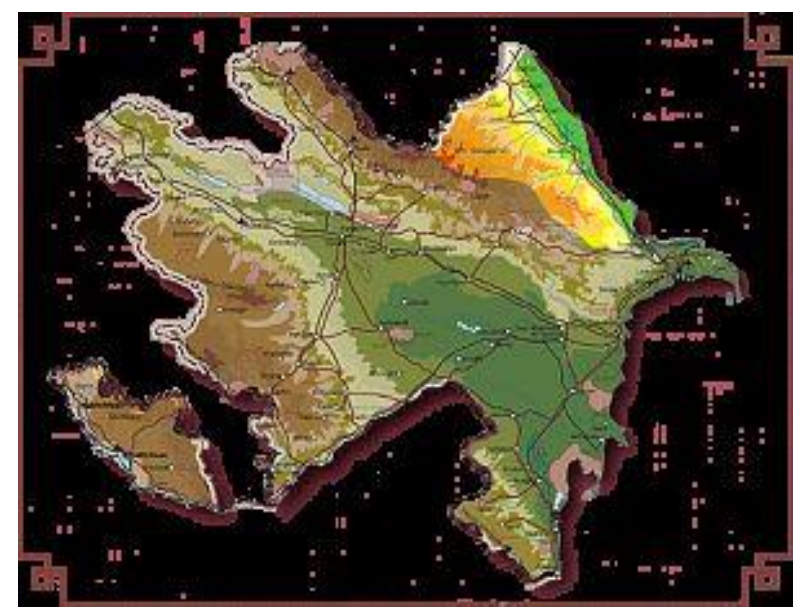


Geologically and geographically, the research region has a rather complex structure, where high mountains and steep slopes alternate with foothills and plains, which in turn contributes to the development of a fairly variegated climate, that is, to a variety of vegetation cover.

The complexity of the geomorphological structure, the presence of steep slopes, as well as the anthropogenic impact, exerts a significant importance to the intensity of surface runoff, which in turn enhances the development of erosion processes, resulting in the creation of wide ravines, which in the final stage are represented by beams, changing the geomorphological appearance of the region as a whole.

In general, according to the Shirvan zone, EM Shikhlinsky [7] distinguishes 3 types of climate:

1) moderately warm, characteristic for the flat areas of the zone with a relatively mild winter;

2) moderately warm wet type with a uniform distribution of precipitation throughout the year, covers the foothills of the zone and

3) cold climate with humid winter, characteristic for the foothill and mountainous area of the zone.

The minimum air temperature is $0.50 \mathrm{C}$ in January, and the maximum temperature is at $23.60 \mathrm{C}$ in July.

The average monthly temperature of the soil varies within the limits of $-10 \mathrm{C}-30,70 \mathrm{C}$. The minimum soil temperature in $-10 \mathrm{C}$ is in January, the maximum is $30,00 \mathrm{C}$ (July) and August is 30,70C months.

The annual precipitation is $692 \mathrm{~mm}$, the greatest amount of which falls in April-June months. The annual value of volatility is $825 \mathrm{~mm}$. The average annual relative air humidity is $71 \%$ fluctuating over the time of year from 59 to $87 \%[2,3,7]$.

It should be recognized that the results of numerous fundamental and applied research on the development of soil erosion and erosion measures have shown that the study of the problem by modern methods is inevitable and naturally it has always been practiced, but it should be noted that with the use of new works of the above-mentioned subjects, experimental and applied research in this field of science, where solutions were sought to prevent it through a comprehensive approach and solving the problem of studies on the development of areas of erosion process.

It is known that far from a complete list of information on soil erosion and measures to combat it at different administrative and economic levels go beyond their visual and other reports of researchers and university textbooks and can provide significant assistance to authors in solving many scientific and applied problems that could not be solved in full to the present time in the republic.

The direction of research on the topic of soil erosion, their mapping and design of erosion control measures, recommended for students, is wide and varied, and can be dlozhena basic building blocks (areas) studies: soil erosion - terminology, classification; conditions that determine the danger of erosion; assessment and mapping of erosion hazardous land; mapping of washed-away soils; protection of soils from erosion; design of anti-erosion measures; ecological, social and 
economic effectiveness of anti-erosion measures; the state of scientific research on the problem of soil protection from erosion in Azerbaijan and other countries of the world.

The natural and climatic conditions of the republic due to the deficiency of water balance contribute to the development of both erosion and deflation, which requires special, progressive methods of mastering soil cultivation, cultivation cultures, melioration and protection of the already small land fund.

It should be noted that in the country the main arrays of lands suitable for irrigated agricultural use already amounting to 1.410 million hectares have been developed and further expansion of arable land is possible only due to the development of less productive lands, which requires excessive protection from soil erosion on the developed lands, their fertility is of great importance for the country. In the process of implementing scientific research carried ou $[2,6]$

The soil erosion is presented as a function of natural and anthropogenic factors and its ecological consequences. The authors proceeded from the assumption that each science requires certain precision and clarity of concepts, and as the new results are achieved, the measures of struggle and the classification of the objects under study are continuously improved.

Many scientists were involved in these issues, for example: Zavaritsky AN (1947); Sobolev SS (1948), KA Alekperov DA (1950-1970), Khalilov M.H. (1972-1989),), Ibragimov AA (19672010), Shvebs GI (1977), Belbibaev ME (1970), Budagov B A.A. (1953-2006), Aliev B.H. (19902016); Zaslavsky MN (1972-1979), etc.), in the works of which the terms derived from the word erosion as well as the concepts of water and wind erosion were treated very widely and not always definitely, and in this connection, many examples of contradictory their interpretation.

Among the authors of the published monographs, MN Zaslavsky, KA Alekperov and BHAliyev are the closest to the authors who, instead of the widely used term, water erosion recommends the use of the term soil erosion to denote both flushing and soil erosion by surface runoff temporal water currents, and the term deflation (wind blowing) instead of wind erosion, which accurately reflects the essence of the phenomenon. [2]

The numerous studies and authors' monographs in the reports show the scales and geography of degradation ochv, the economic damage from erosion is appalling.

The significant structural changes implemented as a result of land reforms in agriculture started in Azerbaijan since 1990 led to a reduction in the area of agricultural land, the removal from agricultural use of vast areas of arable land and forage lands affected by degradation, enormous economic and environmental damage and the threat to subsistence soil as the main means of production and an indispensable component of the biosphere. It is known that the patterns of soil degradation are associated with natural and climatic, lithologic-geomorphological features, as well as the intensity of manifestation of anthropogenic influence.

The Azerbaijan Republic, despite its inadequate study, is characterized by considerable areas of arable land with a very low content of humus, high acidity, and a deficiency in the phosphate regime of soils. 
The results of this study determined that, in Azerbaijan, slope lands occupy 3236 thousand hectares.

The distribution of land in the natural and economic zones of the republic by relief conditions is as follows (table 1.). [1,2].

Table 1: The distribution of land in the natural and economic zones of the Republic by relief conditions

\begin{tabular}{|l|c|c|c|c|c|}
\hline \multirow{2}{*}{$\begin{array}{c}\text { Natural and } \\
\text { economic zones }\end{array}$} & $\begin{array}{c}\text { Suitable for irrigation } \\
\text { under conditions of } \\
\text { relief }\end{array}$ & \multicolumn{4}{|c|}{ Including with slopes } \\
\cline { 5 - 6 } & 2 & $\mathbf{< , 0 5}$ & $\mathbf{0 , 0 5 + 0 , 1 0}$ & $\mathbf{0 , 1 0 + 0 , 2 0}$ & $\mathbf{0 , 2 0 + 0 , 4 0}$ \\
\hline Ganja-Kazakh & 427,50 & 251,0 & 72,8 & 63,70 & 40,00 \\
\hline Shirvan & 680,80 & 522,6 & 50,0 & 66,10 & 42,10 \\
\hline Karabakh-Mila & 749,00 & 567,6 & 80,20 & 47,40 & 53,80 \\
\hline Mugano-Salyan & 429,8 & 402,4 & 2,8 & 17,1 & 7,5 \\
\hline Sheki-Zagatala & 322,7 & 236,5 & 42,7 & 23,8 & 19,7 \\
\hline Lenkoran & 81,5 & 79,5 & 2,0 & - & - \\
\hline Absheron & 52,7 & 31,1 & 21,6 & - & - \\
\hline Cuba-Khachmaz & 203,5 & 179,1 & 24,4 & - & - \\
\hline Upper Karabakh & 133,7 & 24,7 & 27,8 & 37,6 & 43,4 \\
\hline Nakhichevan & 154,2 & 95,3 & 38,0 & 11,2 & 9,7 \\
\hline $\begin{array}{l}\text { TOTAL in the } \\
\text { republic }\end{array}$ & 3235,4 & 2390,0 & 362,3 & 266,9 & 216,2 \\
\hline
\end{tabular}

Thus, the limitation land resources forces to plow even steep slopes. It is assumed that the slopes from 30 to 150 (slopes 0.05-0.25) are sloping, from 150 to 200 (0.25-0.35) -transient to steep, 200steep. Based on the results of research and other scientists, it is implied that 216 thousand hectares of this range of inclines, from suitable for irrigation, are located on steep slopes, 629 thousand hectares in areas with gradients of 0.05 to 0.20 , ha - on flat sections with gradients $\square 0.05$. [2,3] According to the conclusion on the slopes 15-200 it is necessary to place gardens and vineyards. Often, slopes of 30-400 and more degrees, are used for vineyards with the direction of rows along the slope, which creates the most difficult conditions for the operation of agricultural machines and enhanced flushing of the upper fertile soil layer in the inter-row spacing. Therefore, the author believes when laying new gardens and vineyards, one should not go on an apparently more economical way of laying in the direction of the slope. There is also the use of steep slopes for the sowing of grain and forage crops. [2,3,]

Plowing and tillage in such areas are carried out along the slope, which contributes to the intensification of soil washout and a sharp decrease in its fertility.

Many years of systematic, unjustified use of chemical plant protection products in the region, both years of Soviet power, and now especially of pesticides, is one of the main problems in the agricultural zone of the republic as Guba-Khachmas, Ganja-Gazakh, Upper Shirvan and Garabagh. Pollution here soil adversely affects plants, reduce crop yields and loss of potential soil fertility. 
Along with the pollution of ecosystems, it has negative consequences for the population and livestock in the region. Pollution of the environment has become one of the most important tasks of our time, a special role belongs to heavy metals, which have the ability to accumulate in soils and through them to enter food products, while contributing to soil degradation.

The zoning of the republic's territory on irrigation techniques and the degree of erosion of soils in the republics has shown that 14 districts of the republic have a tense situation in which there is a risk of withdrawal of arable land here because of intensive use due to complete soil degradation. In Azerbaijan, there are all types of erosion (including water, mudflow, wind, surface, linear, etc.). Exposure to soil erosion in mountain regions of Azerbaijan is given in the table. (Table 2.)

Table 2: Everification of soil erosion in mountain regions of Azerbaijan

\begin{tabular}{|c|c|c|c|c|c|}
\hline \multirow[t]{2}{*}{ latitude } & \multirow{2}{*}{$\begin{array}{c}\text { Total area in } \\
\text { thousand } \\
\text { hectares }\end{array}$} & \multicolumn{4}{|c|}{ Including the degree of susceptibility to erosion } \\
\hline & & $\begin{array}{c}\text { not subject. } \\
\text { thousand } \\
\text { hectares, \% }\end{array}$ & Slightly & Moderately & Strong \\
\hline Dashkesen & 90,3 & $23,3 / 25,8$ & $18,3 / 20,3$ & $25,6 / 28,3$ & $23,1 / 25,6$ \\
\hline Kedabek & 150,3 & $73,6 / 49,0$ & $20,1 / 13,4$ & $29,8 \backslash 29,8$ & $26,8 / 27,8$ \\
\hline Kelbejar & 124,3 & $48,4 / 38,9$ & $27,2 / 21,9$ & $18,9 / 15,2$ & $29,8 / 24,0$ \\
\hline Lachin & 166,5 & $56,7 / 34,1$ & $26,3 / 15,8$ & $36,7 / 22,0$ & $46,8 / 28,1$ \\
\hline Kubadly & 79,8 & $25,7 / 33,5$ & $6,9 / 8,6$ & $28,7 / 36,0$ & $17,5 / 21,9$ \\
\hline Zangilan & 72,5 & $24,6 / 33,9$ & $16,4 / 22,6$ & $14,6 / 20,2$ & $16,9 / 23,3$ \\
\hline Lerik & 136,5 & $43,6 / 32,2$ & $19,4 / 14,3$ & $27,8 / 20,5$ & $44,7 / 33,0$ \\
\hline Yardymly & 12,5 & $25,1 / 34,6$ & $12,6 / 17,4$ & $10,6 / 14,6$ & $24,2 / 34,4$ \\
\hline $\begin{array}{l}\text { Mountain part } \\
\text { Goranboy }\end{array}$ & $57,6 / 20,8 / 19,5$ & $7,7 / 36,1$ & 33,9 & 13,4 & $9,6 / 16,6$ \\
\hline Julfa & 99,4 & $9,9 / 10,0$ & $16,3 / 16,4$ & $25,3 / 25,5$ & $47,9 / 48,1$ \\
\hline Shahbuz & 81,4 & $61,1 / 19,8$ & $5,4 / 6,6$ & $15,7 / 19,3$ & $14,2 / 54,3$ \\
\hline Ordubad & 92,4 & $7,0 / 7,6$ & $9,5 / 10,6$ & $13,5 / 14,6$ & $62,1 / 67,2$ \\
\hline Absheron & 535 & $57,5 / 10,7$ & $116,8 / 21,8$ & $165,5 / 30,9$ & $195,5 / 36,6$ \\
\hline
\end{tabular}

As can be seen from the table, the most common is water erosion, which develops in ornyh regions more intensively. Soil soils in this and other extent are subject to erosion, which covers 51.0-92.4\% of the land area. In the Shahbuz and Ordubad regions, the soils were heavily eroded and, correspondingly, 54.3 and $67.2 \%$. [2.]

Here it is possible to increase irrigated land up to 1235 hectares. The mountain areas mentioned above, due to the collection of mudflow waters in small reservoirs, more than 1300 hectares wet or unsustainable soils conduct irrigation, which serves to protect mudflow and irrigation erosion in these areas.

In addition, through the reduction of soil erosion, the introduction of a number of measures, incl. the provision of sufficient soil with mineral fertilizers in these areas can be achieved by producing 35.0 thousand tons of wheat, 12.0 thousand tons of tobacco, 10-15 thousand tons of vegetables, 95-100 thousand tons of potatoes, and also by improving the feed base to significantly increase the production of livestock products. [.2,6] 
By mastering the mountain and foothill regions on the sloping lands of Azerbaijan with the use of newly developed irrigation equipment, we accomplished a large volume of long-term research work under the guidance of B .H.Aliyeva [2]. Given the above, it is recommended for the mountain and foothill areas the following methods of irrigation:

1) 1.along furrows with a slit;

2) Sprinkling with low intensity of rain;

3) finely dispersed moistening in combination and without combination with sprinkling;

4) Drip irrigation, etc.

Watering on furrows with a slit of terrain $\square 0,03$. for other crops under the conditions under consideration, the surface watering method is not recommended because of uneconomical water consumption. It should be noted that the creation and development of new progressive irrigation methods is an exception to irrigation erosion, saving irrigation water and not violating environmental protection of the environment. From the foregoing it follows that when developing mountain slopes not only in Azerbaijan but also in the countries of the world, a cautious approach is required to properly select the technique and technology of irrigation recommended for irrigation of tilled crops on lands with slopes. In conclusion, on slopes 15-200 it is necessary to place gardens and vineyards. [24,6]

Often, slopes of 30-400 and more degrees, are used for vineyards with the direction of rows along the slope, which creates the most difficult conditions for the operation of agricultural machines and enhanced flushing of the upper fertile soil layer in the inter-row spacing. Therefore, the author believes when laying new gardens and vineyards, one should not go on an apparently more economical way of laying in the direction of the slope. There is also the use of steep slopes for the sowing of grain and forage crops.

To solve this task, it is necessary to differentiate the lands according to their natural potential and the degree of erosion, and then determine a set of measures to stop the processes of degradation and restoration of soil fertility with subsequent zoning of the territory of the republic according to the degree of erosion with mandatory consideration of all factors affecting the condition and use of land in different types of soil in the republic. on the effectiveness of the anti-erosion measures developed by us and on the prevention of the erosion hazard, which is a complex of protective means that facilitates the regulation of surface runoff, protection of soils from flushing, erosion, and at the same time, the restoration and increase of the fertility of washed-away soils and the involvement of washed-out lands in rational use in the agriculture of the republic.

\section{References}

[1] Aliev G.A. - Soils of the Greater Caucasus within the Azerbaijan SSR., Baku "Elm", 1978, 157 p.

[2] Aliev BH, Aliev ZH Aliev IN Problems of erosion in Azerbaijan and ways to solve it. Publishing house Ziya-CPI "Nurlan". Baku.2000 212p

[3] Babaev M.P., A.M. Djafarov, etc. - The Modern Wounded Cover of the Greater Caucasus, Baku, 2017, 344 p. (in Azeri).

[4] 4.Biodiversity and climate diversity. SVD, UNEP, 2007.http: "www.cbd.int/doc/bioday/2007/ibd2007-booklet-01-ru.pdf"

[5] Vernadsky VI Works on the general history of science [Text] / VI. Vernadsky. Moscow: Nauka, 1908. 
[6] Mamedov G.Sh.Land reform in Azerbaijan: legal and scientific-environmental issues.Baku,2000, $371 \mathrm{p}$.

[7] Mamedov RG - Agrophysical characteristics of soils near the Araxian strip. Baku, 1970, 321 p.

[8] Flint V.E. and others - Conservation and restoration of biodiversity. Moscow: Izd. Scientific and educational-methodical center, 2002, 282 p.9. Shykhlinsky E.M. - The climate of Azerbaijan., Baku, 1968, 341 p.

\footnotetext{
*Corresponding author.

E-mail address: zaakirakademik@ mail.ru
} 